\title{
Research on the Influence of Japanese Multiculture on Japanese Literature
}

\author{
Lili Dong ${ }^{1, a}$
}

${ }^{1}$ College of Foreign Language, Jilin Agricultural University, Jilin, Changchun, China, 130118

${ }^{a}$ email,

Keywords: Influence, Japanese Multiculture, Japanese Literature

Abstract. Along with cultural reflecting activities are carrying out, people begin to realize that blindly worship natural sciences and imperialism expansion cannot bring progress to the world and the worldwide culture began to develop towards diversified. This paper describes the characteristics of Japanese multiculture, clarify a number of points around the impact of multi-cultural on the Japanese literature, we want to play a constructive help on carrying out related work.

\section{Introduction}

In the 20th century natural science idolatry and imperialist expansion led to the unification of values. All this did not bring true happiness to mankind. So, the new target humans and where is it? When we reflect on whether the date of the values of a single real happiness for humanity, globally diversified emerging a pursuit of price wave of people shouting, Culture cultural pluralism is a fundamental state, which I agree with.

It has been the development of history is the fact that the common development of multi-cultural, throughout the history of three thousand years, a profound impact on the culture was not just one, but a variety of cultures simultaneously, in changing the direction of development of the world. Why Chinese culture has a long history, the development of the vitality of today still has an indelible and a very important reason is that it maintained a foreign culture in a friendly attitude and open psychological development and growth process. Such as the Chinese traditional culture of philosophy, art, literature and religious development to some extent, they have benefited from Indian Buddhism, Buddhism in China and India also received a very broad space for development. In addition, European culture is still great vitality today, a crucial reason lies in its significantly the introduction of foreign culture, that enrich their own cultural system, but also injected new blood. All in all, a cultural system, the formation of cultural treasures from different cultural differences, and these differences is to inspire people the source of inspiration and innovation, which together promote the culture of the times and innovation. Cultural differences achievements of cultural diversity, the achievements of the human tapestry.

\section{The Content and Features of Japan Multiculture Policy}

The formation of globalization and the increased population movements multiculture society requires governments to enable foreigners to better integrate into the local community, to protect the rights of these people, provide the appropriate platform for the development of relevant laws, systems and policies. Since the 1990s, multi-cultural phenomenon in Japan and South Korea, has always advocated a "single nation" have also become more prominent. With the reduction of the population, highlighting and raising global awareness of the problem of labor shortage in Japan to enhance international competitiveness, government agencies, academia and speech community, social organizations have started to pay attention to a multiculture society conversion.

After World War II, Japan in respect of domestic cultural diversity, begin to assume its responsibilities are the role of local government reform. Japan and South Korea in the face of Chinese, Korean, Chinese and other people, the old immigrant groups "suffered unfair treatment of the situation, since the early 1970s, Japan's various reform local government with the help of community groups, voluntary organizations expand on" old immigrant groups, "the defense of 
human rights, the abolition of differences abolish fingerprinting and other sports, and in terms of education, health, housing, pensions, employment, also provide some incentives. into the late 1980s, admitted multiculture society formed and ideas implementation of multiculture policies of local government is gradually increasing. The reason, as with the appreciation of the yen, the case highlights the growing labor shortage, the Japanese central government to relax the foreign policy of a great relationship. from the late 1980s, Japan not only from South America received Japanese descent, but also from China, the Philippines and other Asian countries have also accepted a large number of foreign workers, international marriages were and foreign students. Facing the formation of multi-ethnic cultural society, local government majority of foreigners living led many local governments' foreigners to better adapt to local life and integrate into the local community, medical, insurance, education, welfare, etc., giving the Japanese foreign residents the same rights as residents of the region. For example, in order to resolve the difficulties with foreigners conflict, the establishment of specialized agencies and take appropriate action.

Local governments in the promotion and development of multi-cultural society, not only attach importance to relations and cooperation with other local governments, also stressed that the establishment of the inner city and the local civil society organizations, civic groups and cooperation between residents, division of labor and mutual assistance system. The association is responsible for the exchange of information with civil society organizations, civic groups to build a network of relationships between foreigners meeting the organizational, financial and other support. International Association has been developed for local government agencies to promote multiculture coexistence core policies.

As described above, at the local government level, for the people in Japan and South Korea and Koreans, Chinese in Japan and other "old immigrant groups" and the Japanese descendants in South America, trainees, who transnational marriage, foreign students, new immigrant groups, "in many places the Government is very concerned about their lives and work, and to provide a rich and specific support and preferential policies, while at the central government level, concerned and promoting a multiculture society, although did not play a leading role, but for the local government to better Multiculture policies and implement measures to develop a plan, put forward opinions and suggestions, and has also made a contribution.

Nevertheless, Japan in promoting the development of a multiculture society, both at the central government level is lagging behind, or play a leading role in the local government level, are not in the development and improvement of relevant laws, rules and regulations and other institutional safeguards aspects show a positive attitude.

\section{The Characteristics of Japanese Diversified Culture}

For the unity of the composite culture of understanding may be more difficult, but standing on the English point of view and may be relatively easier, Japanese culture is included in the Mono-Bi-Culture. In fact, what it contains it is very simple, from Japan, China introduced many advanced and called the essence of cultural content, and this is to some extent laid the foundation of Japanese culture, and it exhibits the typical composite culture feature. For example: lacquer, English, called Japan; pottery, English is called China and the fact that whether or pottery and last Japanese traditional culture of technology initially from China. Japan, however, puts this composite culture slowly into a unitary culture has its own characteristics, so that the lacquer later become Japan's national essence. In other words, the unity of Japanese culture ultimately formed from the initial composite culture, constantly in later processing, digestion and the process of reunification, gradually revealing its features.

Japan's north-south latitude difference of about twenty degrees, so warm and cold weather large disparity, which also caused people aspire to live in the South of the North, who live in the North and the South full of longing for love. Such a plot in some Japanese literature also mentioned before, such as the West into the "North-South structure of Japanese culture." The "Austrian small mind" this famous Travels forth what southerners in the north spiritual longing, the pursuit and exploration. Japan itself has a different structure of the North-South differences, so the idea of Japanese 
literature, the north and the south there are two factors; but it simply refused in the north, south or is it purely in the pursuit of such a single spirit, but the north and south the high degree of integration between the two parties. In the West into the "North-South structure of Japanese culture", the birth of the flat in the north to the south of the present studied with Habitat should be long, he has been holding the feelings of admiration, but in its soul but has a different philosophy, or even completely opposite. Honda should be in the eyes of the long, sad death, but embrace the concept of people-oriented way of doing things. It is worth mentioning that the Western Jin believes that birth of writers is not an absolute condition, more importantly, a human soul and the spirit of a person attribution point.

In ancient times, the Japanese have always been two different cultural centers. In 1192, the establishment of the Kamakura shogunate, the Tokugawa shogunate ended in 1867. Nearly seven hundred years between the shogunate, Kamakura and Kyoto, Edo and above the two cultural centers are set up today, Kansai and off pattern of the formation of the East with two closely linked. For the problem of cultural centers can also be seen between urban and rural areas. Since they are the city, so there must be rural, in accordance with the rules of development, advanced culture is always attributable to the advanced place, and backward remote areas for advanced culture can only be shared and further spread, spread. Moreover, growth in the city were more wild style yearning for the countryside, perhaps this is the style can make rural life in the city is not so dead, overflowing vitality of the reasons for it! Japan's "Leaves Collection" There is a whole roll of poetry from the country folk, the reason for the name "Dong Song", the reason probably lies in the poetry of this volume are all derived from the eastern part of the country. Meanwhile, in urban and rural areas in a complementary contact, always occupy the capital and cultural center. But since ancient times, Japan has always been the center of two different cultures, so if the Japanese regarded as a circle, then the best and can only be represented by an ellipse. Some scholars believe that such a center circle with two, while Japan's multicultureism is largely in these two points of movement slowly formed; in other words, two circumferential movement in Japan culture. Two base circles generals and the Emperor directly controlled by the formation of a different culture, so as to constitute a special cultural system in Japan is different from other countries.

\section{The Impact of Japanese Multiculture on Japanese Literature}

Many people think that Japan is a lack of self nation, the Japanese are obedient to others and people feel they have no personality. But in fact, the Japanese literature has been a popular a called "private novel" style. In these articles, we can see, inside the "I" word a lot can be said even to the extent of flooding. It is reported that "private novel" creator career mainly some frustrated people, in order to give vent to their emotions through such a literary form to express their dissatisfaction with reality, often there is a masochistic taste. In fact, aside "private novel" aside, Japan is not a lack of self nation, such as Japan and the main content of the song is to talk to inner feelings, and this literature or in a formal setting common form. It can be said that this kind of "my" creative Japanese literature, it is the Japanese adapted to the requirements of the new century, multiculture and open to an extension of their "me."

Historically, Japan is beginning to absorb quite a positive attitude and learn Chinese culture, and in a different culture period, the impact of Chinese culture, Japanese culture that is also different. The impact of this culture for Japanese literature provided the conditions. However, although the impact of Chinese culture for thousands of years in Japan, but also to a certain extent, enrich and develop the Japanese culture, but after the Opium War, especially after the Meiji Restoration, Japan gradually toward modernization, Europe and the United States began with the learning culture civilization.

Such a large multi-cultural and literary research framework, the objective is also to promote the awareness of Japanese literature research methods update. The so-called "multiple meaning of the Japanese literature", both can be understood as the social and cultural diversity of the symbiotic relationship between Japan and literature between, it can also be understood as Japanese literature and film, translation, publishing, interactive dissemination among other styles relationship, but also 
it can be understood as Japanese literature and foreign literature, especially with the nexus of Chinese Literature, Korean Literature, Korean literature between. Of course, the century, this cross-border problem, not limited to the study of Japanese literature, in literary studies in various countries also merited attention.

Japan has various features in the literature, while under the influence of diverse culture, its characteristics have to mention is that when Japanese literature demonstrated openness characteristics. Japan has always been a good at absorbing foreign literary works to enrich their country, which, the author of the article on the front of a concrete analysis. In the mid-19th century, before the Meiji Restoration, Japan boldly absorbs Chinese culture, and this culture is absorbed mainly in the genre of the above literature, such as poetry, prose. Of course, in the absorption of Chinese culture at the same time, Japan also carried out their own innovations, such as creating a variant of Chinese language and kana and other sports. This is also why the author wrote the article before the Japanese nation is by no means a lack of awareness. And until after the Meiji Restoration, Japan set off a wave of learning in Europe and America. In fact, there is also a significant feature in Japan's openness, namely: claims to the then learn powerful country. In the face of the West, the openness of Japanese literature mainly on creative methods of literary works, of course, all kinds of foreign language translation of the novel. Because of these, Japanese literature is among the ranks of the developed capitalist culture medium in less than a century.

\section{Conclusion}

Although the Japanese multiculture has had an impact on Japanese literature in all aspects, an undeniable fact is an unprecedented new period is coming to us. In any case, the development of cultural diversity and the formation of a multiculture state is a necessary trend of the future development of literature, it will strengthen human interaction and understanding based on an interdisciplinary and cross-cultural, which is the only way of forming civilized literature.

\section{References}

[1] Zhong Xijin. Central Public Opinion Agency, 1993

[2] Peng Sue. Research on the History of Sino-Japanese relations, Vol. 12 (2015) No 27, p.74-76

[3] Qian Xiyuan, Jing Jianfen. Shandong Normal University, Vol. 30 (2014) No 19, p.144-145

[4] Wang Kuailiang. Yunnan Nationalities University, Vol. 29 (2008) No 27, p.21-23

[5] Zhang Gongxu, Sun Jing. Japanese Study and Research, Vol. 8 (2013) No 27, p.57-60 